\title{
Emphysematous Pyelonephritis in a 32-Year-Old Diabetic Female
}

\author{
Muhammad Abdur Rahim ${ }^{1}$, Mehruba Alam Ananna ${ }^{1}$, Tabassum Samad ${ }^{2}$, \\ Tufayel Ahmed Chowdhury ${ }^{2}$, Wasim Md. Mohosinul Haque ${ }^{3}$, Sarwar Iqbal ${ }^{3}$ \\ Received: January 5, 2015 Accepted: April 12, 2015 \\ doi: http://dx.doi.org/10.3329/jemc.v5i2.23387
}

\begin{abstract}
Emphysematous pyelonephritis is a rare, severe, necrotizing renal parenchymal infection characterized by gas accumulation in kidney(s) with or without involving surrounding tissues. Patients with diabetes mellitus are the usual sufferers. Here we describe a case history of a young Bangladeshi diabetic lady who presented with dysuria, fever and abdominal pain. Investigations confirmed left sided emphysematous pyelonephritis. She responded to and recovered with intravenous antibiotics.
\end{abstract}

Key words: Diabetes mellitus; Emphysematous pyelonephritis

J Enam Med Col 2015; 5(2): 122-124

\section{Introduction}

Emphysematous pyelonephritis (EPN) is a severe and life-threatening infection of the renal parenchyma, collecting system or perinephric tissue and is characterized by presence of gas in the parenchymal tissue. ${ }^{1}$ Diabetes mellitus (DM) is an important risk factor being responsible in $95 \%$ cases or even more. ${ }^{2,3}$ Other risk factors include urinary tract obstruction, anatomic deformities of urinary tract, neurogenic bladder, polycystic kidneys, drug overuse, alcoholism, end-stage renal disease and immune-suppression. ${ }^{2,4}$ Presentation is like that of acute pyelonephritis. Imaging studies can readily detect gas in kidney(s), computed tomographic (CT) scan can best delineate extension of gas. ${ }^{5}$

\section{Case report}

A 32-year-old diabetic lady presented with a 4-day history of dysuria, fever and supra-pubic pain. She took diclofenac sodium for pain before being hospitalized.
She was mildly anemic with normal hemodynamic status and normal temperature. She had mild suprapubic tenderness and tenderness over left renal angle on percussion. She had uncontrolled diabetes, anemia, neutrophilic leukocytosis, thrombocytopenia, raised erythrocyte sedimentation rate, C-reactive protein, blood urea, serum creatinine and low serum sodium, bicarbonate and albumin (Table I). She had glycosuria, albuminuria, pyuria and hematuria (Table I). Abdominal ultrasonogram (USG) showed swollen and hypoechoeic left kidney with echogenic components with dirty shadows within parenchyma, calyces and pelvis of left kidney suggesting left sided emphysematous pyelonephritis (Fig 1) and minimal pleural effusion on left side. Chest radiography showed elevated left hemidiaphragm (Fig 2). CT scan confirmed left sided EPN (Fig 3A and 3B). Urine culture revealed growth of nonEnterococcus spp. Blood culture did not show growth of any organism.

1. Assistant Professor, Department of Nephrology, Bangladesh Institute of Rehabilitation in Diabetes, Endocrine and Metabolism (BIRDEM) General Hospital, Dhaka

2. Registrar, Department of Nephrology, BIRDEM General Hospital, Dhaka

3. Associate Professor, Department of Nephrology, BIRDEM General Hospital, Dhaka

Correspondence Muhammad Abdur Rahim, Email: muradrahim23@yahoo.com 


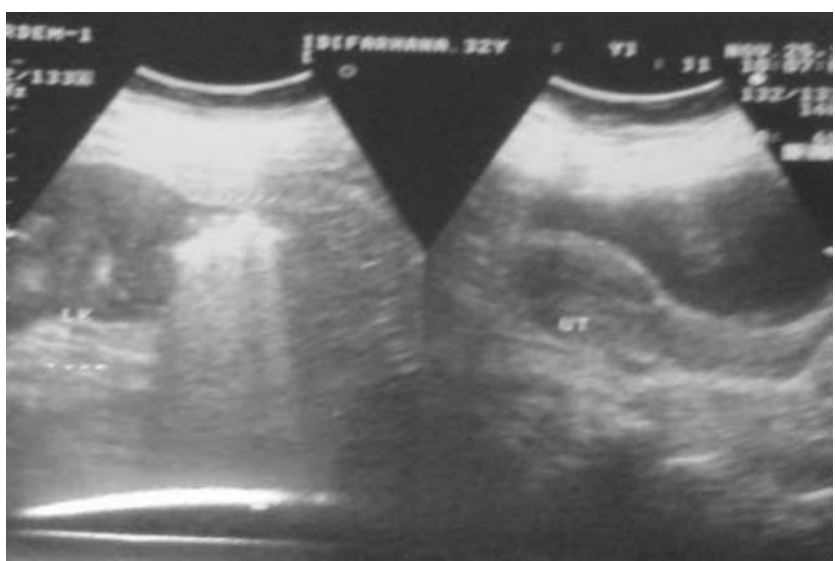

Fig 1. Ultrasonogram showing echogenic components with dirty shadows within parenchyma, calyces and pelvis of left kidney suggesting left sided emphysematous pyelonephritis

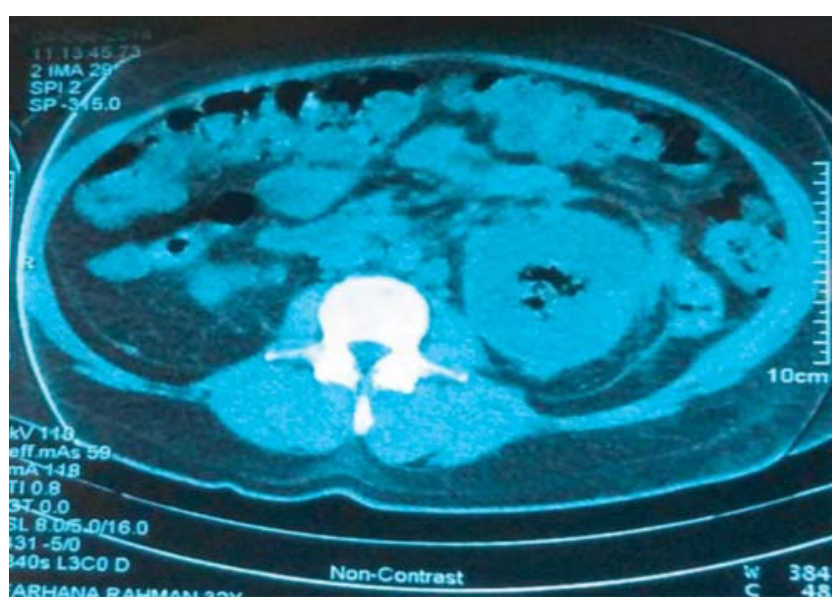

Fig 3A. CT scan of abdomen showing gas in left renal pelvis and parenchyma

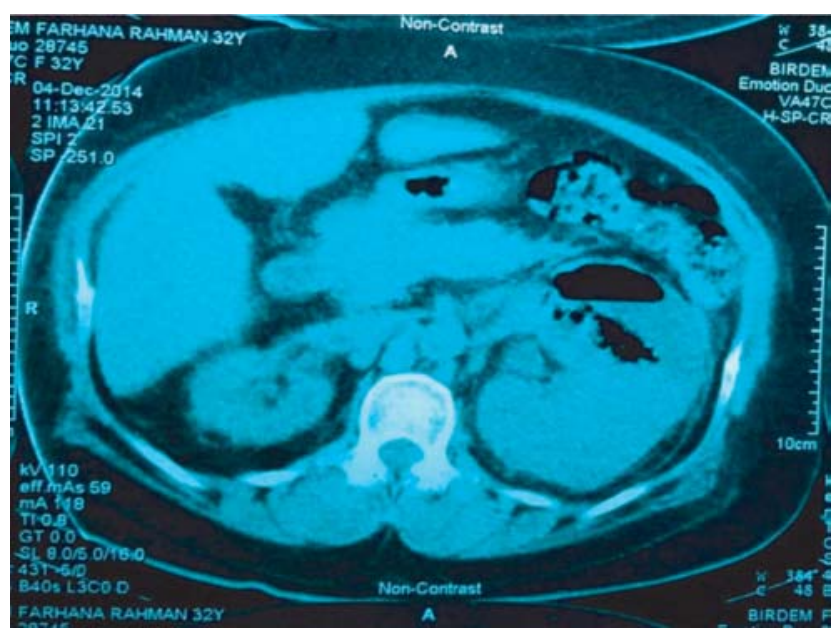

Fig 3B. CT scan of abdomen showing gas in left renal pelvis and parenchyma

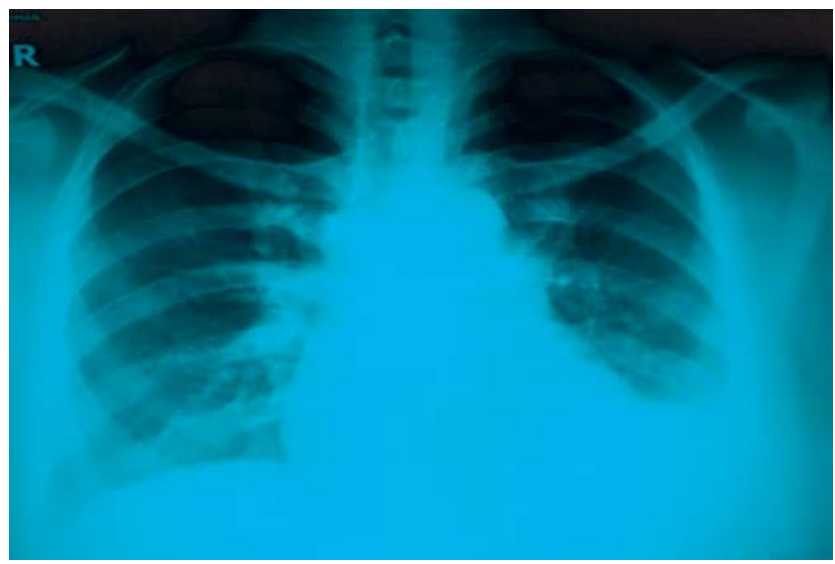

Fig 2. Chest X-ray (postero-anterior view) showing elevated left hemidiaphragm

After getting urine culture report, her antibiotic was changed from ceftriaxone to meropenem according to antibiotic sensitivity. Other supportive treatment included intravenous fluid, insulin and paracetamol. She was discharged on $15^{\text {th }}$ day after admission. Her serum creatinine came back to $1.2 \mathrm{mg} / \mathrm{dL}$. Follow up USG after one week showed presence of air in left renal pelvis but less than in previous scan. She was on meropenem for four weeks and cured completely both clinically and radiologically.

Table I: Abnormal laboratory findings of the patient with emphysematous pyelonephritis

\begin{tabular}{|c|c|c|}
\hline Laboratory tests & Patient's results & Reference values \\
\hline Random blood glucose (mmol/L) & 20.2 & $<11.1$ \\
\hline $\operatorname{HbAlc}(\%)$ & 15.5 & $<7$ \\
\hline \multicolumn{3}{|l|}{ Urine } \\
\hline Glucose & +++ & \\
\hline Protein & Trace & \\
\hline Pus cells/HPF & Plenty & \\
\hline $\mathrm{RBC} / \mathrm{HPF}$ & Plenty & \\
\hline Culture & $\begin{array}{l}\text { Growth of non-Enterococcus spp. } \\
\qquad\left(1 \times 10^{5} \mathrm{CFU} / \mathrm{mL}\right)\end{array}$ & \\
\hline $\mathrm{Hb}(\mathrm{gm} / \mathrm{dL})$ & 9.5 & $11.5-16$ \\
\hline Total white blood cells/cmm & 23,700 & $4000-11,000$ \\
\hline Neutrophils (\%) & 85 & $40-70$ \\
\hline Platelets/cmm & 25,000 & $1,50,000-4,50,000$ \\
\hline ESR (mm in $1^{\text {st }}$ hour) & 110 & $<20$ \\
\hline $\mathrm{CRP}(\mathrm{mg} / \mathrm{L})$ & 24 & $<6$ \\
\hline Blood urea (mg/dL) & 92 & $10-50$ \\
\hline Serum creatinine (mg/dL) & 4.7 & $0.67-1.2$ \\
\hline Serum Na $(\mathrm{mmol} / \mathrm{L})$ & 122 & $136-145$ \\
\hline Serum $\mathrm{TCO}_{2}(\mathrm{mmol} / \mathrm{L})$ & 12 & $23-27$ \\
\hline Serum albumin (gm/L) & 28 & $35-57$ \\
\hline
\end{tabular}




\section{Discussion}

EPN was first described in $1898 .{ }^{6}$ Since then various names like 'renal emphysema', 'pneumonephritis' were used and the term 'Emphysematous pyelonephritis' was adopted in $1962 .{ }^{7}$ Escherichia coli and Klebsiella pneumoniae are predominant organisms and rarely gas forming organisms like Clostridia are reported to cause EPN. ${ }^{2,8}$ In our case urine culture report revealed growth of non-Enterococcus spp. and treatment was started with meropenem. DM is an important risk factor. Rarely EPN is the presenting feature of DM. ${ }^{5,9}$

Gas formation in EPN results from fermentation of glucose by Enterobacteriaceae. ${ }^{2}$ Plain radiograph can show air in regions of kidneys, USG can detect gas in kidneys, but $\mathrm{CT}$ has highest sensitivity and specificity. ${ }^{5,10}$ Huang \& Tseng ${ }^{2}$ gave classification of EPN depending upon CT findings - class 1, gas in the collecting system only; class 2 , gas in the renal parenchyma without extension to extra-renal space; class $3 \mathrm{~A}$, extension of gas or abscess to perinephric space, class 3B, extension of gas or abscess to pararenal space and class 4, bilateral EPN or solitary kidney with EPN. Our patient had class 2 EPN. The higher the class, the worse the prognosis. ${ }^{2}$ Moreover, thrombocytopenia, acute kidney injury (AKI), disturbance of consciousness, shock and conservative approach with antibiotic only are risk factors for bad prognosis. $^{2,3}$ Our patient had thrombocytopenia and AKI and she responded well to antibiotics and other supportive treatment. It is to be noted that interventions should not be delayed whenever indicated, eg, class 3B or more and any class with more than 2 risk factors. ${ }^{2}$

Treatment consists of antibiotic alone, percutaneous catheter drainage combined with antibiotic treatment or nephrectomy. Mortality is high, even up to $40 \%$ when antibiotic alone is tried as sole treatment. ${ }^{2}$ In conclusion, it can be said that any patient with DM having upper urinary tract infection, if not responding to antibiotics, should be suspected and investigated promptly for EPN.

\section{References}

1. Pontin AR, Barnes RD, Joffe J, Kahn D. Emphysematous pyelonephritis in diabetic patients. Br J Urol 1995; 75: 71-74.

2. Huang JJ, Tseng CC. Emphysematous pyelonephritis: clinicoradiological classification, management, prognosis and pathogenesis. Arch Intern Med 2000; 160: 797-805.

3. Ubee SS, McGlynn L, Fordham M. Emphysematous pyelonephritis. BJU Int 2011; 107: 1474-1478.

4. Shokeir AA, El-Azab M, Mohsen T, El-Diasty T. Emphysematous pyelonephritis: a 15-year experience with 20 cases. Urology 1997; 49(3): 343-346.

5. Rafailidis V, Karadimou V, Liouliakis C, Kougioumtzoglou D. Emphysematous pyelonephritis: a case report. Hippokratia 2013; 17(4): 373-375.

6. Kelly HA, MacCallum WG. Pneumaturia. J Am Med Assoc 1898; 31: 375-381.

7. Schultz EH, Klorfein EH. Emphysematous pyelonephritis. J Urol 1962; 87: 762-766.

8. Christensen J, Bistrup C. Emphysematous pyelonephritis caused by Clostridium septicum and complicated by a mycotic aneurysm: case report. Br J Radiol 1993; 66: 842-843.

9. Nasr MA, Kishk AG, Sadek EM, Parayil SM. A case report of emphysematous pyelonephritis as a first presentation of diabetes mellitus. Iran Red Cres Med J 2013; 15(12): e10384.

10. Bamanikar A, Dhobale S. Fever with abdominal pain and diabetes - is it emphysematous pyelonephritis? Malays J Med Sci 2014; 21(3): 85-88. 